$D \approx 10^{3}$ A., $\lambda=0.058$ A., this will not exceed $\pi$ unless $V_{h k l}$ is greater than about 3 volts, which corresponds to a strong reflection. Minima are thus found at

$$
\theta-\theta_{0}= \pm d_{h k l} \sqrt{\frac{m^{2}}{\bar{D}^{2}}-\frac{\mid \overline{\left.V_{h k l}\right|^{2}}}{4 \pi^{2} k^{2}}},
$$

where $m=1,2,3$. . etc.

With large $m$ or small $D$, the second term under the root can be neglected compared to the first, thus leading to (2), Kossel and Möllenstedt's formula. It is easily seen that the dynamical correction term has the greatest relative influence on the distance between the first minima on either side of the maximum at $\theta_{0}$; in the distances between minima on the same side of $\theta_{0}$ the correction terms cancel to a great extent, in accordance with experiment.

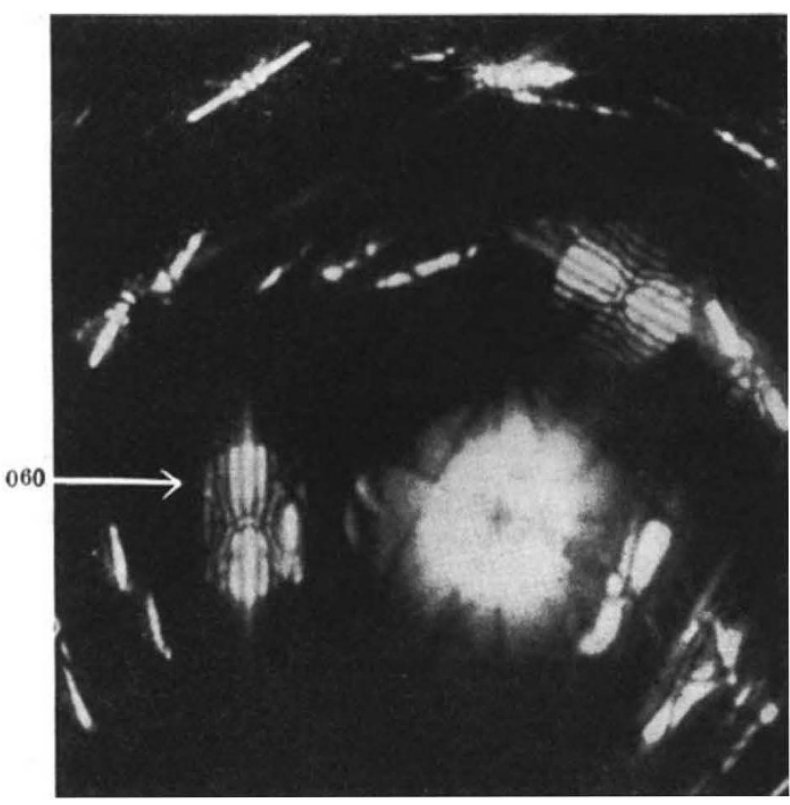

Fig. 1.

TRANSMISSION PATTERN FROM MICA WITH CONVERGENT ELECTRON BEAMS. 1

To test (2a), $V_{h k l}$ has been computed from the anomalous distances ${ }^{4}$ in the diffraction spot on the left-hand side of Fig. 1, corresponding to the reflection $(060)$. (In the figure it is seen that the position of the bands shifts when crossed by a Kikuchi line. This effect being caused by terms neglected in $(2 a)$, the distances between minima must be measured outside these regions.)

$$
\frac{\theta_{+1}-\theta_{-1}}{\left(\theta_{m+1}-\theta_{m}\right)_{m=\infty}}=2 \sqrt{1-\frac{\mid \overline{\left.V_{060}\right|^{2}}}{4 \pi^{2} k^{2}} D^{2}}=1 \cdot 2,
$$

where $\left(\theta_{m+1}-\theta_{m=\infty}\right)_{m=\infty}$ has, as a rather crude approximation, been taken from the average value of the bands $\theta_{2}-\theta_{1}$ and $\theta_{3}-\theta_{2}$. With $D=900 \mathrm{~A}$. and $\lambda=0.058$, we find

$$
V_{060}=2 \cdot 3 \text { volts. }
$$

On the other hand, $V_{h k l}$ was evaluated from the known atomic positions in mica, the data of Jackson and West ${ }^{4}$ for muscovite having been used :

$$
V_{060}=\frac{d^{2}{ }_{060} e}{\pi a b c \sin \beta} \cdot \Sigma i\left(Z_{i}-F_{i}\right) e^{2 \pi i .6 Y_{i} / b}=2 \cdot 1 \text { volts, }
$$

in striking agreement with the value found above.
It is thus shown to be possible to determine structure factors simply by measuring distances between minima in the fine structure of a diffraction spot, without any intensity measurement. The applicability in practice of this very remarkable way of measuring structure factors will be confined to crystal flakes of sufficiently uniform thickness; when $D$ is not sufficiently constant, the position of the minima will shift within the region of coherence of the beam, so that the fine structure will disappear.

Carolina H. MacGillavry.

Crystallographic Laboratory,

University, Amsterdam.

Dec. 21.

${ }^{1}$ Kossel, W., and Möllenstedt, G., Ann. Phys., 36, 113 (1939).

${ }^{2}$ Bethe, H. A., Ann. Phys., 87, 55 (1928).

${ }^{3}$ Ewald, P. P., Ann. Phys., 49, 1, 117 (1916) ; 54, 519 (1917). v. Laue, M., Erg. d. exalt. Naturw., 10, 133 (1931). Kohler, M., Ann. Phys., 18, 265 (1933).

4 Jackson, W. W., and West, J., Z. Krist., 78, 211 (1931).

\section{Selective Oxidation of Aluminium Alloys}

IN a recent communication ${ }^{1}$, S. Dobiński and M. Niestuchowski state that "an explanation of such striking facts as the formation of a layer of pure $\mathrm{MgO}$ on the surface of an alloy containing barely one atom of magnesium for about 3,000 atoms of aluminium, chemical arguments are of little help. As a matter of fact, the heat of oxidation of aluminium (namely 190) is much greater than that of magnesium (143) or beryllium (131). 'Preferential' oxidation in the sense of greater chemical affinity of magnesium or beryllium for oxygen, or reduction of the previously formed $\mathrm{Al}_{2} \mathrm{O}_{3}$ by beryllium or magnesium, can thus scarcely be considered as a probable hypothesis".

The writers overlook the fact that in this case must be compared heats of oxidation which are related to the same amount of oxygen. The heats of oxidation of magnesium and beryllium mentioned above must be compared with the heat of oxidation of aluminium, also related to one atom of oxygen (namely, 126). The chemical affinity of beryllium and magnesium for oxygen is thus greater than that of aluminium, and the preferential oxidation of magnesium and beryllium is in accordance with the difference in chemical affinity of the three oxides.

N. V. Philips' Gloeilampenfabrieken, H. BienfatT.

Eindhoven.

Dec. 22

${ }^{1}$ NatURe, 144, 510 (1939).

\section{The Primus Stove at High Altitudes}

THE risk of carbon monoxide poisoning from Primus stoves, discussed by Prof. Yandell Henderson and Mr. J. McCullough Turner in NATURE of January 20, was realized at least eighteen years ago. The Mount Everest party of 1922 was warned about this, on Prof. Georges Dreyer's advice. He pointed out how the danger might be aggravated at high altitudes owing to oxygen scarcity, and consequently less complete combustion. 